\title{
Article \\ Optimal Management of Energy Consumption in an Autonomous Power System Considering Alternative Energy Sources
}

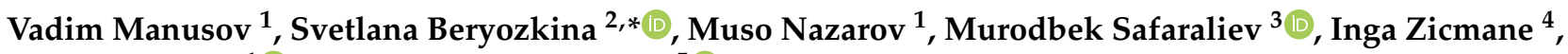 \\ Pavel Matrenin ${ }^{1}$ (D) and Anvari Ghulomzoda ${ }^{5}$ (D) \\ 1 Department of Industrial Power Supply Systems, Novosibirsk State Technical University, \\ 630073 Novosibirsk, Russia; manusov@corp.nstu.ru (V.M.); musso-6556@mail.ru (M.N.); \\ matrenin.2012@corp.nstu.ru (P.M.) \\ 2 College of Engineering and Technology, American University of the Middle East, Kuwait \\ 3 Department of Automated Electrical Systems, Ural Federal University, 620002 Yekaterinburg, Russia; \\ murodbek_03@mail.ru \\ 4 Faculty of Electrical and Environmental Engineering, Riga Technical University, LV-1048 Riga, Latvia; \\ inga.zicmane@rtu.lv \\ 5 Department of Automated Electric Power Systems, Novosibirsk State Technical University, \\ 630073 Novosibirsk, Russia; anvar_4301@mail.ru \\ * Correspondence: svetlana.berjozkina@aum.edu.kw
}

Citation: Manusov, V.; Beryozkina, S.; Nazarov, M.; Safaraliev, M.; Zicmane,

I.; Matrenin, P.; Ghulomzoda, A. Optimal Management of Energy Consumption in an Autonomous Power System Considering Alternative Energy Sources. Mathematics 2022, 10, 525. https:// doi.org/10.3390/math10030525

Academic Editors: Nicu Bizon, Francisco Chiclana and Mario Versaci

Received: 4 December 2021 Accepted: 3 February 2022 Published: 8 February 2022

Publisher's Note: MDPI stays neutral with regard to jurisdictional claims in published maps and institutional affiliations.

Copyright: (C) 2022 by the authors. Licensee MDPI, Basel, Switzerland. This article is an open access article distributed under the terms and conditions of the Creative Commons Attribution (CC BY) license (https:// creativecommons.org/licenses/by/ $4.0 /)$.

\begin{abstract}
This work aims to analyze and manage the optimal power consumption of the autonomous power system within the Pamir region of Republic of Tajikistan, based on renewable energy sources. The task is solved through linear programming methods, production rules and mathematical modeling of power consumption modes by generating consumers. It is assumed that power consumers in the considered region have an opportunity to independently cover energy shortage by installing additional generating energy sources. The objective function is to minimize the financial expenses for own power consumption, and to maximize them from both the export and redistribution of power flows. In this study, the optimal ratio of power generation by alternative sources from daily power consumption for winter was established to be hydroelectric power plants (94.8\%), wind power plant $(3.8 \%)$, solar photovoltaic power plant $(0.5 \%)$ and energy storage $(0.8 \%)$; while it is not required in summer due to the ability to ensure the balance of energy by hydroelectric power plants. As a result, each generating consumer can independently minimize their power consumption and maximize profit from the energy exchange with other consumers, depending on the selected energy sources, thus becoming a good example of carbon-free energy usage at the micro- and mini-grid level.
\end{abstract}

Keywords: autonomous power system; generating power consumer; hydroelectric power plant; optimal power consumption; wind power plant; solar photovoltaic power plant; energy storage

\section{Introduction}

In the last decade, a depletion of the fossil fuel reserves and growing demand for power energy have been the most important issues in a global context. Modern energy systems are going through a period of serious changes associated with the transition from centralized, top-down structures with a heavy dependence on fossil fuels to distributed, decentralized, environmentally friendly energy solutions in accordance with the Paris Climate Agreement 2016, which was aimed at combating climate change and depletion of natural resources as well as energy security at both national and continental scale. Therefore, the use of renewable energy sources (RES) as an alternative to traditional energy sources is becoming a prioritized direction for energy policy in most countries around the world [1,2].

By making "green" decisions about power generation, researchers are doing everything possible to obtain the most reliable and efficient way of generating energy by using RES. Therefore, increased attention to technologies used for the RES on such a large scale 
has led to a constant cost reduction of distributed technologies for the production, storage and conversion of renewable energy [2,3]. The use of RES is especially attractive and suitable for supplying electricity to remote areas, which operate in an autonomous mode from both technical and economic points of view. For instance, the introduction of renewable energy technologies with their rational use could help in supplying power energy to areas with a weak fuel base and poor transport conditions, and solve the problem of efficient use of consumed resources and involvement in the energy balance of regions of previously unused energy sources and resources, to improve the ecological situation in the places of heat and power energy production. As result, these activities and measures will contribute to the accelerated economic development of these regions and improve the social and living conditions of their population, which corresponds to the UN's Sustainable Development Goal 7, on ensuring universal sustainable access to reliable energy sources for settlements remote from national networks by creating autonomous, low-voltage, low-inertia local networks based on renewable energy sources $[2,4,5]$.

The mass adoption of microgrids reached $1.4 \mathrm{GW}$ in 2015 and is expected to increase to $8.8 \mathrm{GW}$ by 2024 [6]. Such considerable interest is due to their potential advantages in terms of facilitating the integration of the RES into both the existing and new energy systems. For example, the microgrid multiple energy carrier refers to an interconnected energy system that provides a platform for connecting various energy vectors from various sources to meet various energy needs in remote regions, and is applicable in various sectors, including commercial, industrial and military, considering the set goals, load types, geographical and climatic conditions. The model extends the concept of original microgrids focused on electricity demand, with the desire to use the interaction between different energy vectors to virtually meet all energy needs of communities, while increasing the sustainability, reliability, efficiency and availability of the RES [1].

Electrification of such isolated regions can be provided either by one type of renewable energy or by hybrid renewable energy, where solar photovoltaic coupled with wind energy sources is the most used combination today because of their complementarity. However, it is well known that the generation scheme of technologies operating on intermittent energy sources, such as solar and wind, can change greatly, quickly and unpredictably, unlike traditional technologies, for which generation can be adjusted to produce a certain amount of energy at a certain time based on fluctuations in electricity demand. As a result, network stability problems limit the possibilities of using these RES on a scale that allows them to reach their full potential in the absence of backup power at times when wind or solar photovoltaic $(P V)$ energy suddenly becomes unavailable, and/or without providing energy management services that allow network operators to use cheaper energy generated outside the peak of consumption to meet peak electricity demand $[1,7,8]$.

Hydropower is a type of clean renewable energy with instant power adjustment and flexibility in storage and discharge. The complementary work of hydro-wind-photovoltaic hybrid power plants $(H P P / W P P / P V)$ is becoming increasingly relevant for modern energy systems. Thus, the regions with rich hydropower resources and conditions acceptable for energy generation by wind generators and photovoltaic cells have significant potential for the development of modern energy. However, there is a problem; in regions where energy resources are usually far from load centers, barriers requiring long-distance transmission of electricity remain, which undermines the economic feasibility of using such energy sources, and strong fluctuations associated with the flow and generation of $P V$ and wind energy lead to uncertainty in additional operations and, as a result, due to the inherently unstable nature of generation of the RES, a control system of a sufficiently high level of its execution is crucial [3,9-13].

In this regard, the possible solutions are as follows:

- Energy storage (ES), for example, energy storage in HPP and compressed air, chemical batteries and active load management;

- Geographical diversification of installation sites;

- Combination of energy sources; 
- Application of high-precision methods of weather and load forecasting [12].

Therefore, the optimal design of a hybrid energy system based on the RES is a complex task, which includes a feasibility study, model-based design, process modeling (simulation), as well as the integration of several hybrid RES, a hybrid energy storage system and a hybrid controller for automation to ensure the reliability of a power supply [14].

The purpose of this study is to develop a system and manage optimal power consumption in the autonomous power system within the Pamir region of the Republic of Tajikistan, based on alternative energy sources.

The work is structured as follows: Section 1 presents the introduction and relevance of the topic; Section 2 describes a problem analysis, problem statement and review of the scientific literature; Section 3 contains information about the ES serving as the object of research; Section 4 introduces the proposed method and algorithm of optimization of energy consumption modes; and Section 5 provides an analysis of obtained results and their discussion; Section 6 includes conclusions.

\section{Problem Statement and a Brief Overview of the Proposed Approaches}

\subsection{Optimization of Electricity Production Based on Renewable Energy Sources}

The issue of the optimal management of power energy production/consumption in modern distribution systems is becoming especially relevant in the era of Smart grid. In addition, the operation of autonomous power systems with a high share of the RES can create significant problems with system balancing. Decentralized integration of the RES based on the Smart grid (intelligent energy system) is presented as the most promising way to increase the stability and reliability of the latter, in a cost-effective way $[15,16]$, especially since it is autonomous, intelligent and integrated renewable energy systems that underlie the "energy for all" initiatives aimed to provide modern energy services to coastal, island and mountainous regions and also in a broader sense, to rural/peripheral regions [1].

Hybrid renewable energy systems (HRES) can vary significantly in the type and number of generation sources, consumers, installed capacity, operating conditions and many other factors. Currently, conditions and opportunities have been created for power consumers to independently choose generation sources, where renewable energy sources in combination with energy storage devices can serve for autonomous and local power energy systems. Such systems are characterized by absence of a centralized energy source and high uncertainty of renewable and alternative energy sources, which implies an independent solution to the optimization problem of the most profitable combination of renewable and alternative energy sources to minimize the material, technical and financial costs of each generating electric consumer [14].

Several works are devoted to the tasks of optimizing the operation of generating power plants of power supply systems using the RES, as well as a technical and economic assessment of energy supply to isolated consumers, in which either an economic justification is given for the efficiency of connecting to centralized power supply, or the possibility of using local small energy sources is considered. Zones of expediency of centralized and decentralized power supply are given depending on electricity tariffs and the cost of diesel fuel [17-19]. This approach makes it possible at the regional level to identify those areas for which it is necessary to conduct a detailed assessment of the use of a technologically possible and economically feasible energy supply option. At the local level, specific energy supply options for each consumer are determined, the order of input of energy sources, the composition of equipment and the necessary investments. The results of research for various regions allow us to form proposals for promising areas of scientific and technological progress in the field of small-scale energy, to assess the appropriate scale of implementation and the equipment market of economically attractive projects.

\subsection{Mathematical Methods of the Optimization}

The authors of a number of works, using mathematical modeling methods, propose the creation of a technical and economic model to analyze the technical and economic feasibility 
of multi-energy complementarity. In order to solve the problem of continuous power supply at photovoltaic power plants, the authors in [11,20-22] use the theory of complementation of hydro and solar energy, which allows to solve a problem of intermittent and unstable solar energy generation. To reduce risks and increase reliability, such type of power systems is additionally supplied with the energy storage devices $[23,24]$. Due to the instability of wind resources, the relevant scientists have combined hydro-accumulating power plants with WPPs, striving for an optimal mode of complementary work, and maximizing profits. In [25], modeling of economic indicators of further integration of photovoltaic systems is described considering technical limitations. The economic feasibility of a large-scale hybrid hydroelectric power plant, including the transmission of energy over long distances, is presented in [10].

It should be noted that when optimizing the modes of power energy systems, the Lagrange multiplier method and gradient methods have become the most widespread. The dynamic programming method and some others are also used. Currently, alternative algorithms for optimizing modes are being developed by using fuzzy logic methods and evolutionary algorithms. For example, optimization of the modes of joint operation of solar and thermal power plants is presented in [26], where Lagrange multipliers were used to derive the optimization equation.

For isolated systems, models should be created to optimize the distributed generation management system, including the RES. Such models allow to optimize the network operation according to various parameters. Various methods for optimizing the operating modes of power energy systems and networks are discussed in [27-29] whereby an optimal method for determining the size of renewable energy parks and ES in a hybrid power system is proposed. The genetic algorithm is used to find optimal solutions for both renewable farms and energy storage devices. It is noted that among the traditional tasks of optimizing the modes of electric power systems and power supply systems of industrial facilities, the selection of the best configurations of electric networks, the distribution of loads between power sources of both existing and projected power supply systems as well as the rationalization of the use of energy resources are highlighted. Examples of the application of existing optimization methods are analyzed.

In general, the optimization process can be divided into single-purpose and multipurpose methods. For example, a method for optimizing the size of renewable energy parks is proposed together with an economic analysis for a need for charging from the grid up to 50,000 plug-in electric vehicles [30]. However, the process that limits the impact of fluctuations in the capacity of a renewable energy farm on the utility network is not analyzed. Another method, which is based on a cost-benefit analysis for the optimal size of an energy storage system in a microgrid, is proposed in [31], but the corresponding size of a renewable energy farm is not specified. In addition, the energy storage system included only the use of batteries that can fail in situations of high-power fluctuations. An optimal method for determining the size of a hybrid power system with a wind solar battery is proposed for both autonomous and network mode (without an ultracapacitor) in [32].

It should be noted that most of the initial research in this area is devoted to the analysis of the short-term operation of small-scale/autonomous power systems for those cases when the requirements for the quality of electricity production seem less important. The study conducted in [13] aimed to analyze a long-term optimization model for hybrid hydro/photovoltaic systems, considering the stability of output power and total electricity generation simultaneously by creating a multi-purpose optimization model for long-term operation of a hydroelectric power plant/photovoltaic system, which is then optimized using a modified version of the non-dominated sorting genetic algorithm. In turn, to improve the long-term additional operational characteristics of a large-scale hybrid $H P P$, methods of long-term stochastic optimization were developed in [11], which simultaneously consider the uncertainty of the flow and output power of a photovoltaic installation. A multi-purpose optimization model was created to maximize the total energy production and guaranteed speed. The model was then solved using stochastic dynamic programming 
to obtain operational solutions. This study focused on the long-term complementary operation of hybrid power plants with $H P P$, given the uncertainty in both the flow and capacity of solar photovoltaic energy.

\section{Data and Materials}

\subsection{An Assessment of Energy Resources of the Pamir Region of Republic of Tajikistan}

Pamir is one of the richest regions of Tajikistan in terms of hydropower energy reserves. Power energy reserves are concentrated on the territory of this region, which are estimated at 32.5 billion $\mathrm{kWh}$. However, approximately $0.6 \%$ of this potential is currently being used. Low development indicates a weak level of economic development and considerable potential for region growth in the future. The open hydropower resources of small rivers and watercourses of the region are so large that when the level of their use reaches $20 \%$, the Pamirs will turn into one of the richest mining regions of the country. The hydroelectric potential of the Pamirs represents the economic efficiency of its use and commercial benefits to justify the construction of small HPPs. The main factors delaying the use of energy resources are as follows: assessment of the impact of hydropower construction on the environment, the complex nature of the use of watercourse water resources and the energy market in Central Asia. It should be noted that small and even medium-sized Pamir rivers are either insufficiently or not studied at all in terms of energy potential $[17,33,34]$.

The network of hydrometeorological observations in Tajikistan is not dense enough; therefore, the real potential of wind energy remains not fully explored.

For example, wind speed measurements were not carried out at the level of $30 \mathrm{~m}$ from the earth's surface, where the potential of wind energy can be 10-20\% higher than at the level of $10 \mathrm{~m}$. Despite this, the wind energy potential of Tajikistan reaches $25-150$ billion $\mathrm{kWh} /$ year according to experts' opinion [18,19]. The authors state the fact that the meteorological network of Tajikistan is still underdeveloped since a need for meteorological data on the wind and sun has not been sufficiently demanded due to the non-use of renewable energy sources. However, the authors have currently managed to collect the necessary prehistory of statistical data on wind and solar insulation from meteorological stations allocated in the main sites of industrial and domestic power consumers, which, as can be assumed, can be refined.

The total solar radiation reaches $700-800 \mathrm{~W} / \mathrm{m}^{2}$ or $7500-8000 \mathrm{MJ} / \mathrm{m}$, when there are clear skies. These parameters are much higher in mountainous areas, especially in the Eastern Pamirs, where the population has limited opportunity to use the hydropower resources $[35,36]$.

\subsection{General Characteristics of the Pamir Power System}

The operation and control of the modes of power stations and networks, as well as the energy generation, transmission and distribution in Tajikistan is carried out by an Open Joint-Stock Holding Company (OJSHC) "Barki Tojik", except for Gorno-Badakhshan Autonomous Region (GBAR). The power supply system of the GBAR operates based on the renewable and alternative energy sources; it was transferred from the company "Barki Tojik" to the control of the private electric company "Pamir Energy" in 2002 for a period of 25 years under a concession agreement and the system began to function in isolated (autonomous) mode from the main power system.

Currently, "Pamir Energy" manages eleven HPPs, of which the larger ones are Pamir-1 and Khorog HPPs as well as nine small HPPs with a total installed capacity of $43.5 \mathrm{MW}$, which is clearly reflected in Table 1. Three HPPs from the above list (Pamir-1 HPP, Khorog HPP and Namangut HPP) work for the network (for a total load), and Pamir-1 HPP and Khorog HPP are in a cascade on the Gunt River, and Namangut HPP is located on another river, the Panj River. The rest of these 11 stations are operating offline in separate areas. 
Table 1. Information about the SHPP located on the territory of GBAR.

\begin{tabular}{|c|c|c|c|c|c|}
\hline Substation No. & HPP Name & $\begin{array}{l}\text { Installed Capacity, } \\
\text { kW }\end{array}$ & $\begin{array}{c}\text { Number of } \\
\text { Hydraulic Units }\end{array}$ & Design Pressure, m & $\begin{array}{l}\text { Water Flow through the Unit, } \\
\qquad \mathrm{m}^{3} / \mathrm{s}\end{array}$ \\
\hline 1 & HРP Pamir-1 & 28,000 & 4 & 79.6 & 10.1 \\
\hline 2 & HPP Khorog & 9000 & 5 & 59 & 3.55 \\
\hline 3 & HPP Namangut & 2500 & 2 & 36 & 3.5 \\
\hline 4 & HPP Vanch & 1200 & 2 & 21.5 & 3.5 \\
\hline 5 & HPP Ak-Su & 640 & 2 & 9 & 5 \\
\hline 6 & HPP Shugnan & 832 & 2 & 10 & 5.5 \\
\hline 7 & HPP Savnob & 80 & 1 & 72 & 0.1 \\
\hline 8 & HPP Siponj & 160 & 2 & 130 & 0.31 \\
\hline 9 & HPP Andarbek & 300 & 1 & 23 & 1.8 \\
\hline 10 & HPP Techarv & 360 & 1 & 110 & 0.59 \\
\hline 11 & НРP Kalai-Humb & 208 & 2 & 10.8 & 1.55 \\
\hline
\end{tabular}

The examined power system uses the transmission lines with a voltage of $35 / 10 / 0.4 \mathrm{kV}$ and total length of $2609 \mathrm{~km}$. The Pamirs' small hydroelectric power plants (SHPP) are characterized by insufficient availability of water resources in winter months, thus the HPP, which are working under a given load schedule, use a natural water flow without their redistribution in the daily interval. As a result, the HPP cannot cover the maximum loads of the daily schedule during morning and evening peaks. In winter, when the maximum demand for electricity is observed in all regions of the Pamirs, the SHPPs that do not have large-capacity reservoirs provide almost minimal power $[17,33,34]$.

Figure 1 shows the geographical location of the stations in the Pamir power system for illustrative representation of the territorial location of the generating nodes.

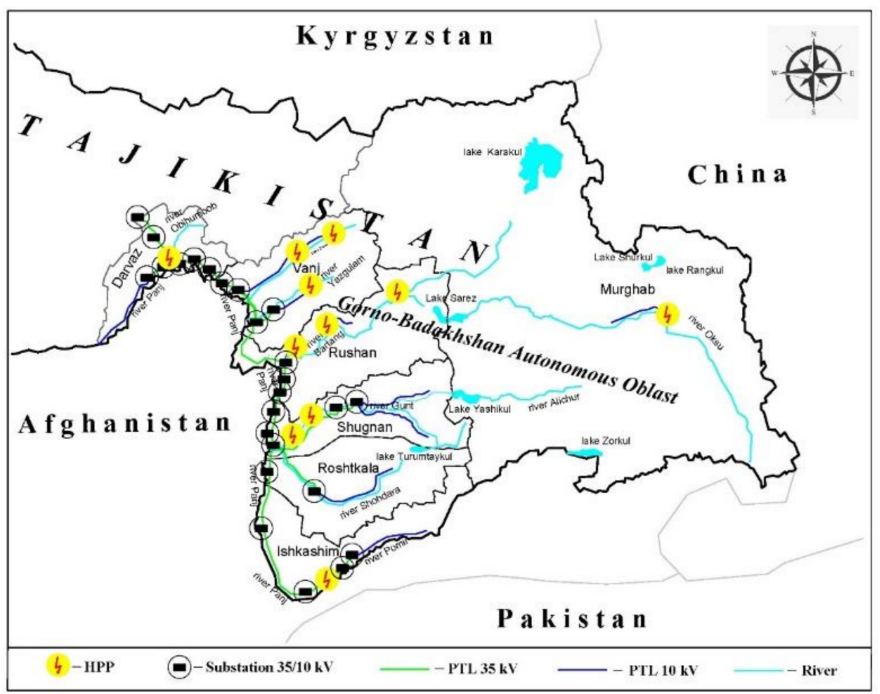

Figure 1. Geographical location of the Pamir power energy system.

Due to the efficient and economical RES, the autonomous power supply of the region can be provided by forming a hybrid power system of HPP /WPP/PV / ES system, in which, for an optimal combination of various renewable energy sources, methods of both technical and economic analysis are used. The development of an optimization model of the power consumption has been considered for an autonomous hybrid electric power system (EPS) based on the GBAR example (Figure 2). 


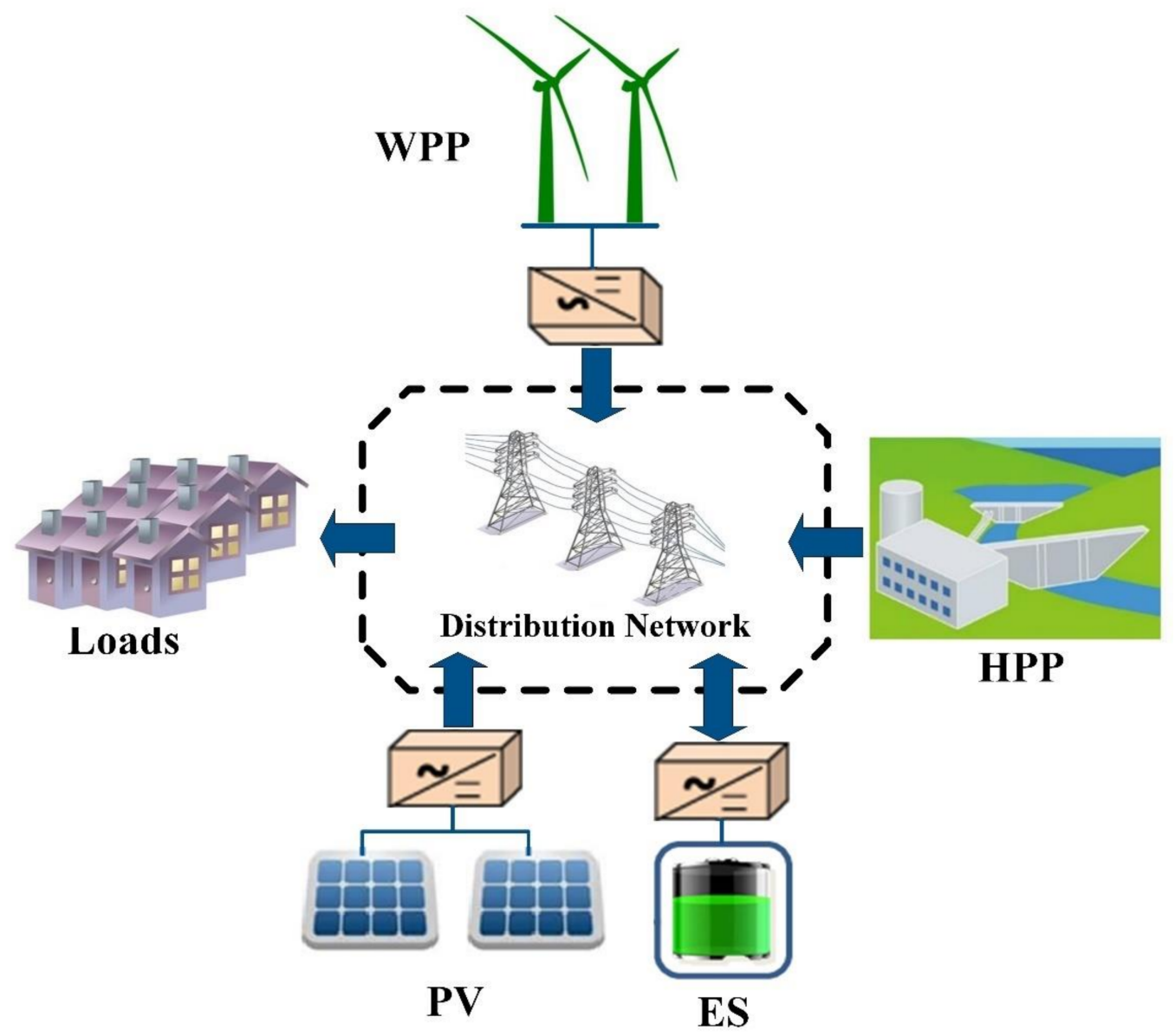

Figure 2. Overview of the proposed hybrid power system.

\subsection{An Assessment of the Energy Balance of the Pamir Region}

To assess the energy potential of the considered autonomous power energy system of the Pamirs, it is necessary to assess the possibility of using alternative energy sources in the daily interval. At the same time, the essential difference between the modes of this system is that it is energy-deficient in the winter and in an energy-surplus in the summer. In this regard, the most characteristic days have been chosen for both winter and summer periods. Two modes are selected characterizing the extreme points. During the summer, when there is a maximum energy of small rivers, the hydro resources are sufficient to fully cover the load, especially during the flood period. This also creates good conditions for the electricity export. During the winter, the electricity consumption for heating purposes increases, and the energy of water for activating the reservoirs can be used only by $30-40 \%$. On these characteristic days, a power shortage is created during peak power consumption modes, exports are significantly limited, and energy storage is fully utilized. Ideally, it would be advisable to build a pumped storage station, which is a continuation of this work. To optimize power consumption modes, the statistical data of wind speed, solar insolation, power generation by HPP due to water resources and a daily load schedule were used for the selected characteristic days [37].

The power of the WPP depends on the wind speed, which varies greatly with time, weather conditions and terrain surface [16]. The dependence of the power and speed of the wind passing through a swept area of wind turbine is expressed as follows:

$$
P=\frac{1}{2} \rho A V^{3} C_{p}(\lambda),
$$


where $\rho$ is the air flow area $\left(\mathrm{kg} / \mathrm{m}^{3}\right)$, depending on the temperature and air pressure; $A$ is the surface area swept by blades $\left(\mathrm{m}^{2}\right) ; V$-wind speed $(\mathrm{m} / \mathrm{s}) ; C_{p}$ is the efficiency coefficient of the wind turbine; and $\lambda$-speed coefficient.

For the power system, the total installed capacity of the wind park of $10 \mathrm{MW}$ was selected, which consists of 20 wind turbines with a capacity of $500 \mathrm{~kW}$ each. According to the datasheet, power generation begins with a wind speed of $3 \mathrm{~m} / \mathrm{s}$. When the speed reaches $12 \mathrm{~m} / \mathrm{s}$, the rated power is generated. In the range of $12-25 \mathrm{~m} / \mathrm{s}$, the rated power of wind turbines is maintained. A detailed location selection of wind turbines considering the terrain and wind speed could be carried out in accordance with the recommendations provided in [14].

Figure 3 shows wind speed and solar insolation data for a typical winter day in the examined region. The highest values of wind speed coincide approximately with the morning load peak leading to a wind energy use in the morning. It is obvious that the greatest power due to solar energy can be obtained from 8 to $18 \mathrm{~h}$ in a daily profile. This roughly corresponds to the duration of the electrical load during a working day. The total power of the solar panels was selected as $5 \mathrm{MW}$ with an efficiency of $22.5 \%$.

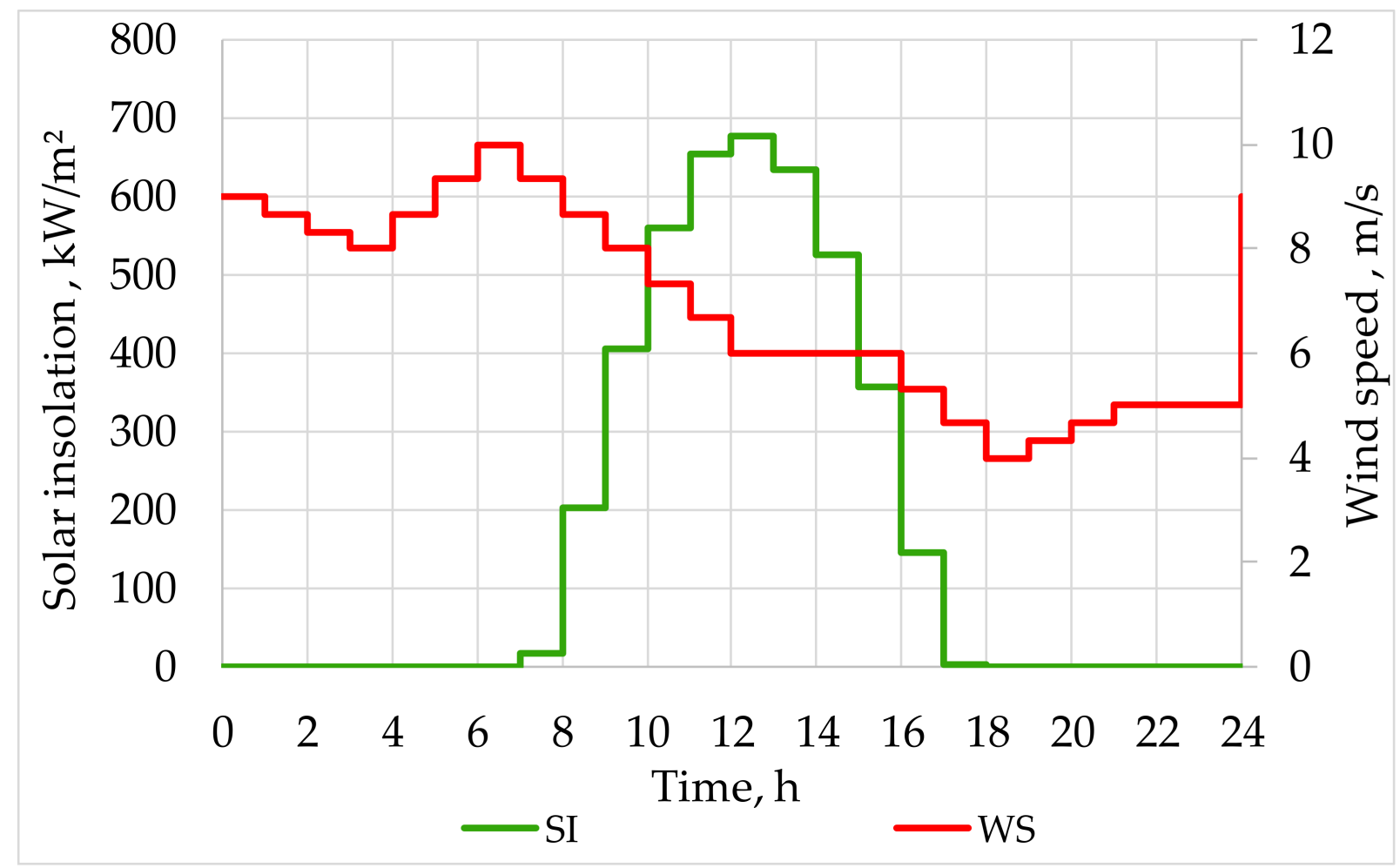

Figure 3. Wind speed and solar insolation data of a typical winter day.

For a typical winter day, the power generation by HPP at the expense of water resources, the daily load schedule, the power generated by the wind power plant, as well as the power generation by solar panels are selected as initial information and given in Figure 4. Additionally, the initial power of the energy storage at the beginning of the day is $2000 \mathrm{~kW}$, which is optimally consumed or accumulated in accordance with the optimization algorithm in order to minimize the financial costs of electric consumers. 


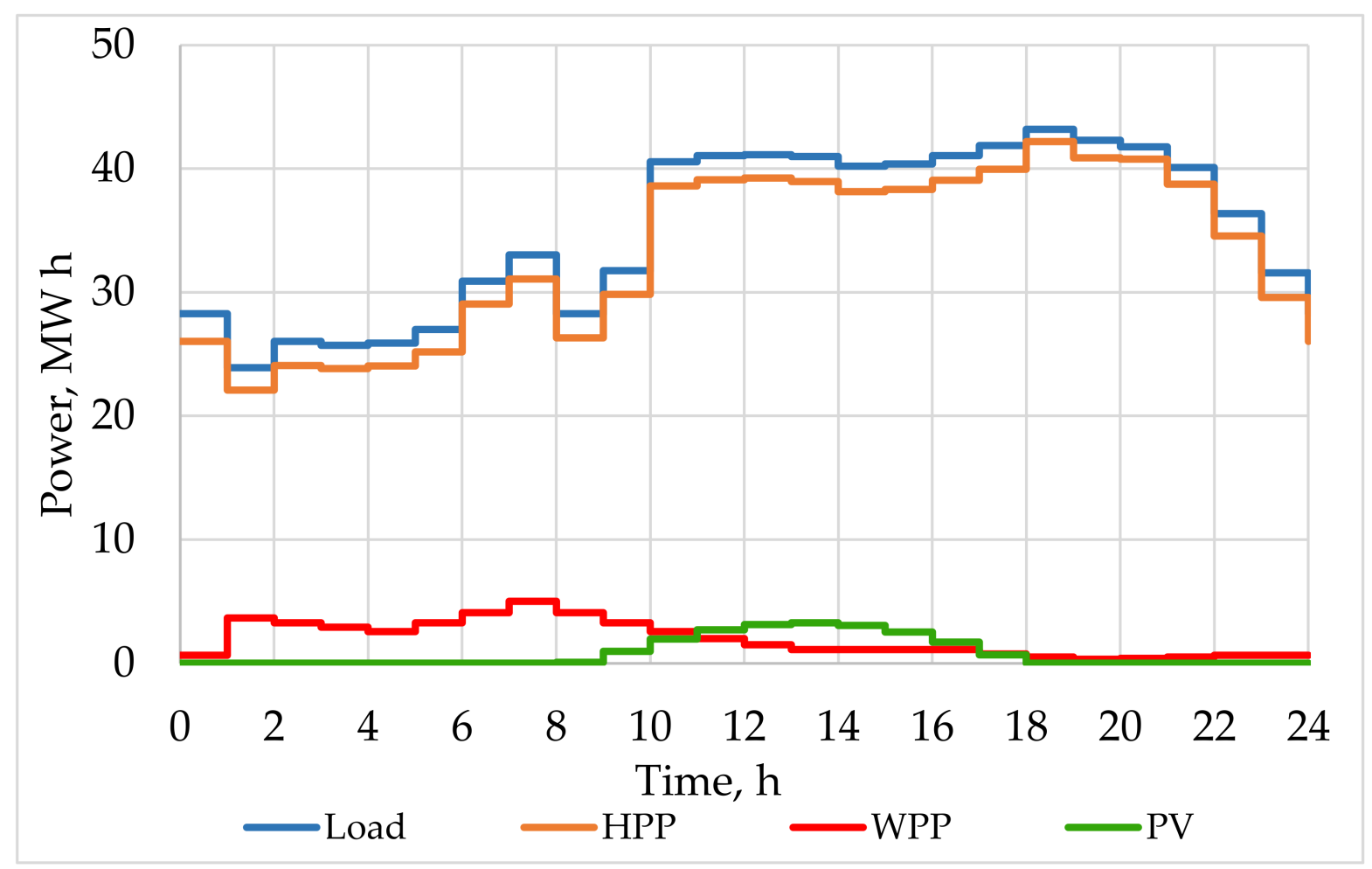

Figure 4. The initial information of the energy balance for a typical winter day.

\section{Methodology}

\subsection{A Formation of a Mathematical Model of the Optimal Power Consumption}

The main objective of this work is to offer an optimal connection of 11 potentials of large and small hydropower together with wind and photovoltaic systems in a form of a hybrid system, which will increase the reliability of the system and decrease the investment costs.

Consider an example of optimizing the generation structure of the GBAR power system, as an isolated power supply system, from the cost minimization point of view in terms of electricity generation. The power balance equation for a such autonomous system will have the following form:

$$
P_{H P P}+P_{W P P}+P_{P V} \pm P_{E S}=P_{L O A D}+\Delta P,
$$

where $P_{H P P}$ is capacity of $H P P ; P_{W P P}$ is capacity of $W P P ; P_{P V}$ is capacity of $P V ; P_{E S}$ is capacity of energy storage $(E S) ; P_{L O A D}$ is load power consumption; and $\triangle P$ is power energy losses during both the transmission and distribution.

The balance equation in integral form is given as follows:

$$
\int_{0}^{24} P_{H P P}(t) d t+\int_{0}^{24} P_{W P P}(t) d t+\int_{0}^{24} P_{P V}(t) \pm \int_{0}^{24} P_{E S}(t)=\int_{0}^{24} P_{L O A D}(t)+\int_{0}^{24} \Delta P(t) .
$$

The task of minimizing the financial costs of an individual generating power consumer is solved based on the minimization of the objective function, the hourly measurements of power and energy of which presumably numerically coincide as follows:

$$
\sum_{i=0}^{24} R_{i} \cdot P_{H P P}+\sum_{i=0}^{24} R_{i} \cdot P_{W P P}+\sum_{i=0}^{24} R_{i} \cdot P_{P V} \pm \sum_{i=0}^{24} R_{i} \cdot P_{E S}=\sum_{i=0}^{24} P_{i L O A D}+\sum_{i=0}^{24} \Delta P_{i}
$$


where $R_{i}$ is hourly power energy consumption from this type of generation source; $P_{H P P}$ is power consumption from HPP in the $i$-th hour; $P_{W P P}$ is power consumption from WPP in the $i$-th hour; $P_{P V}$ is power consumption from $P V$ in the $i$-th hour; and $P_{E S}$ is power consumption from ES in the $i$-th hour.

Due to the fact that it is advisable to minimize the financial costs of each individual consumer, Equation (4) must be written taking into account the individual cost of each alternative or renewable energy source:

$$
\left(C_{H P P} \cdot \sum_{i=0}^{24} R_{i} \cdot P_{H P P}+C_{W P P} \cdot \sum_{i=0}^{24} R_{i} \cdot P_{W P P}+C_{P V} \cdot \sum_{i=0}^{24} R_{i} \cdot P_{P V} \pm C_{E S} \cdot \sum_{i=0}^{24} R_{i} \cdot P_{E S}\right) \rightarrow \min ,
$$

where $C_{H P P}=0.02 \mathrm{EUR} / \mathrm{kW} \cdot \mathrm{h}$, the cost of power energy generated at the $H P P$; $C_{W P P}=0.03 \mathrm{EUR} / \mathrm{kW} \cdot \mathrm{h}$, the cost of power energy generated at the WPP; $C_{P V}=0.036 \mathrm{EUR} / \mathrm{kW} \cdot \mathrm{h}$, the cost of power energy generated at the $P V$; and $C_{E S}=0.043 \mathrm{EUR} / \mathrm{kW} \cdot \mathrm{h}$, the cost of power energy accumulated on $E S$.

In the case of an energy surplus, a similar following equation can be derived to maximize the income:

$$
\left(k \cdot C_{H P P} \cdot \sum_{i=0}^{24} G_{i} \cdot W_{H P P}+k \cdot C_{W P P} \cdot \sum_{i=0}^{24} G_{i} \cdot W_{W P P}+k \cdot C_{P V} \cdot \sum_{i=0}^{24} G_{i} \cdot W_{P V} \pm k \cdot C_{E S} \cdot \sum_{i=0}^{24} G_{i} \cdot W_{E S}\right) \rightarrow \text { max }
$$

where $G_{i}$ is an excess of the power energy in the $i$-th hour for each energy source; and $k$ is the coefficient of profitability from the sale of the power energy.

Retrospective studies of this autonomous power system allows us to establish some specific values of possible power generation by energy sources, which, based on long-term observations, can be obtained as the following values for a working winter day, namely: $P_{M A X ~ H P P}=43.5 \mathrm{MW}, P_{M A X W P P}=10 \mathrm{MW}$ (rounded) and $P_{M A X P V}=6 \mathrm{MW}$. Based on the power balance during the maximum hours of the daily load schedule, energy storage devices have been selected, taking into account the unpredictability of the generation of "green energy". For this reason, the above-given equations must be solved under constraints in the form of inequalities, namely:

$$
\begin{gathered}
0 \leq P_{H P P} \leq 43.5 \mathrm{MW} ; 0 \leq P_{W P P} \leq 10 \mathrm{MW} \\
0 \leq P_{P V} \leq 6 \mathrm{MW}
\end{gathered}
$$

Moreover, the possibility of transferring power energy to Afghanistan could be considered as an additional power consumer, which buys excess energy in case of GBAR autonomous power system surplus. An additional important circumstance should be noted, in particular, the balance of power and energy in the system under consideration can also be balanced by limiting the transmitted power to Afghanistan, but it cannot be a source of generation in the foreseeable future.

\subsection{Solution Method and Production Rules}

Software was developed in order to perform calculations. The program algorithm is based on the linear programming method by using the following conditions in the form of product rules. The "production rule" means the expression of some cause-and-effect relationships between events, phenomena or changes, which are expressed in the form of "IF, ... THEN, ...", where the initial condition (cause) is the antecedent, then the result (consequence) is the consequent. These rules are limited to the form of equalities and inequalities. For example, if the total capacity of an HPP fully covers the electricity demand of an autonomous system, then other sources are not involved. If the total capacity of the HPP is insufficient to cover the required load, then the next energy source is, as a priority, attracted in terms of the electricity cost; in our case, it is the WPP. The production rules for $H P P, W P P, P V$ and $E S$ were established as stated below. 
1. Production rules for $H P P$ :

IF $\left(P_{H P P}<P_{L O A D}\right)$ THEN

$C P_{H P P}=P_{H P P}$ and $R P_{H P P}=0$

OTHERWISE

$C P_{H P P}=P_{L O A D}$ and $R P_{H P P}=P_{H P P}-P_{L O A D}$

2. Production rules for WPP:

IF $\left(C P_{H P P}<P_{L O A D}\right)$ THEN

IF $\left(P_{W P P}>0\right)$ THEN

IF $\left(C P_{H P P}+P_{W P P}>P_{L O A D}\right)$ THEN

$C P_{W P P}=P_{L O A D}-C P_{H P P}$ and $R P_{W P P}=P_{W P P}-C P_{W P P}$

OTHERWISE

$C P_{W P P}=P_{W P P}$ and $R P_{W P P}=0$

OTHERWISE

$C P_{W P P}=0$ and $R P_{W P P}=0$

OTHERWISE

$C P_{W P P}=0$ and $R P_{W P P}=P_{W P P}$

3. Production rules for $P V$ :

IF $\left(C P_{H P P}+C P_{W P P}<P_{L O A D}\right)$ THEN

IF $\left(P_{P V}>0\right)$ THEN

IF $\left(C P_{H P P}+C P_{W P P}+P_{P V}>P_{L O A D}\right)$ THEN

$C P_{P V}=P_{L O A D}-\left(C P_{H P P}+C P_{W P P}\right)$ and $R P_{P V}=P_{P V}-C P_{P V}$

OTHERWISE

$C P_{P V}=P_{P V}$ and $R P_{P V}=0$

OTHERWISE

$C P_{P V}=0$ and $R P_{P V}=0$

OTHERWISE

$C P_{P V}=0$ and $R P_{P V}=P_{P V}$

4. Production rules for $E S$ :

IF $\left(C P_{H P P}+C P_{W P P}+C P_{P V}<P_{L O A D}\right)$ THEN

IF $\left(P_{E S}>0\right)$ THEN

IF $\left(C P_{H P P}+C P_{W P P}+C P_{P V}+P_{E S}>P_{L O A D}\right)$ THEN

$C P_{E S}=P_{L O A D}-\left(C P_{H P P}+C P_{W P P}+C P_{P V}\right)$ and $R P_{E S}=P_{E S}-C P_{E S}$

OTHERWISE

$C P_{E S}=P_{E S}$ and $R P_{E S}=0$

OTHERWISE

$C P_{E S}=0$ and $R P_{E S}=0$

OTHERWISE

$C P_{E S}=0$ and $R P_{E S}=P_{E S}$

For a power energy storage device, the rules for the production of its charge from various alternative energy sources are formulated separately, taking into account restrictions in the form of equalities and inequalities. At the same time, the following priority of energy storage was established: initially from the HPP, then from WPP and further from $P V$.

Accurate losses' computation in the electrical network requires calculation of the steady state at each hourly interval. The advantage of the proposed algorithm of minimizing financial costs of electricity consumption does not imply such complex calculation. It is assumed that the losses are included in the load and conditionally range from 5 to $10 \%$.

Figure 5 presents the UML (Unified Modeling Language) class diagram of the developed software. 


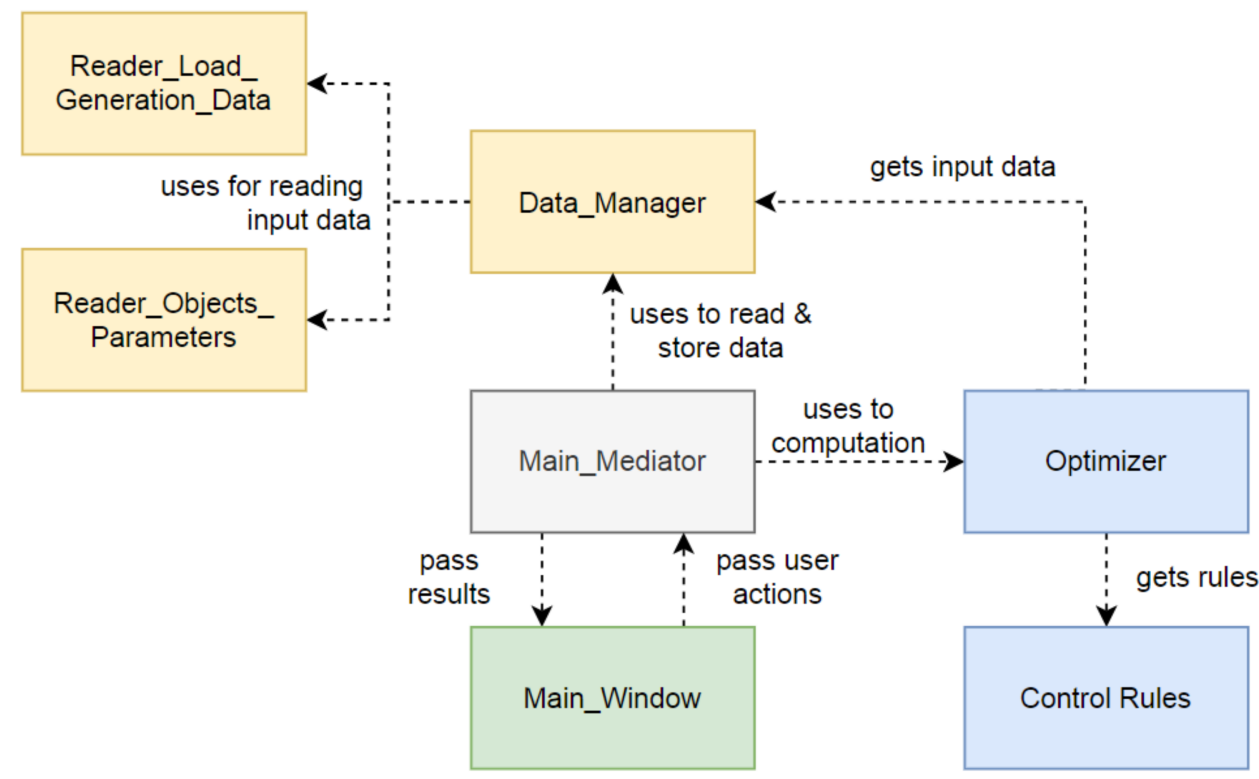

Figure 5. The UML class diagram of the developed software.

There are three main modules: Data (pale orange color), Graphical User Interface (light green), Computation (light blue), and the Mediator synchronizing all modules with each other. The modular architecture makes it easy to change individual parts in the system, for example, to add a new data format, change the optimization algorithm or modify the base of control rules.

\section{Results and Discussion}

The examined autonomous power system, the main generation sources of which are the HPPs of small rivers, has been adopted as a renewable energy source, and the WPPs and solar $P V$ power plants have been adopted as alternative sources. An energy storage device is considered as a balancing source. Energy conservation in the storage device is necessary due to some unpredictability of power generation by alternative sources and is structurally performed based on lithium-ion batteries. The electrical diagram of the considered autonomous power system, including the installed alternative sources, is shown in Figure 6.

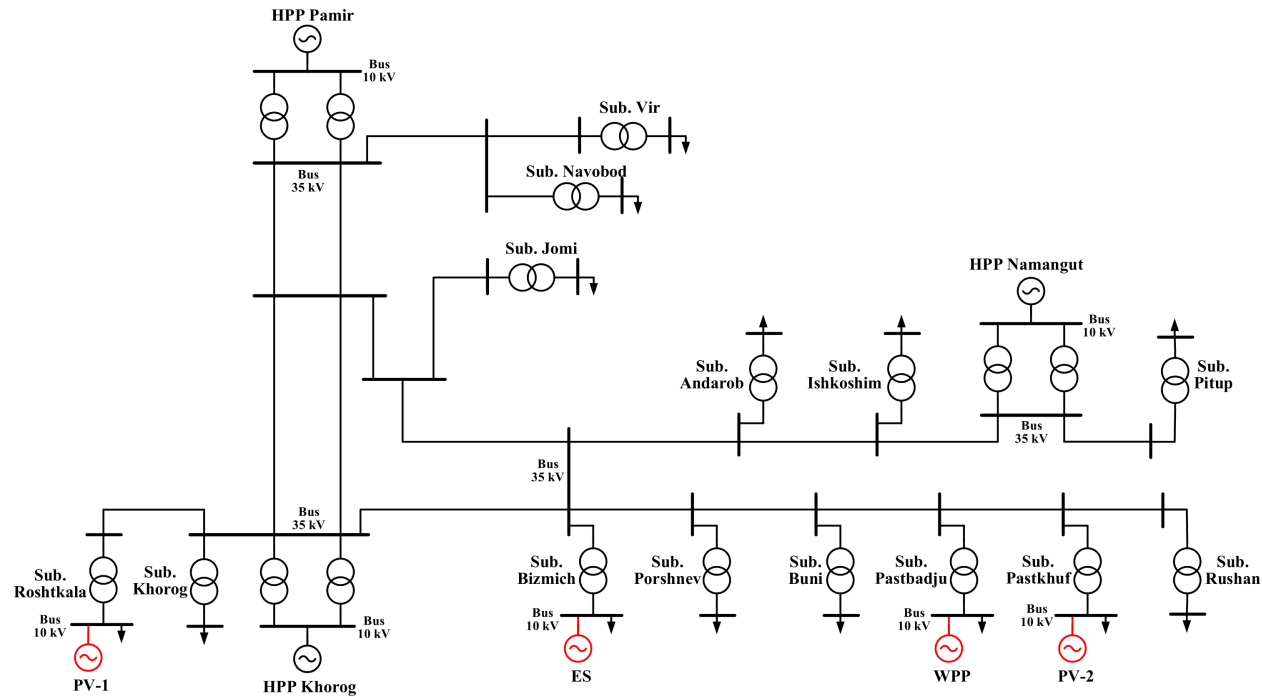

Figure 6. An electrical scheme of the considered autonomous power system. 
According to the proposed algorithm, computations can be performed for each day in a certain seasonal interval of the year based on the product rules and the developed program. The calculation results of the optimal energy consumption for the examined case are shown in Figure 7.

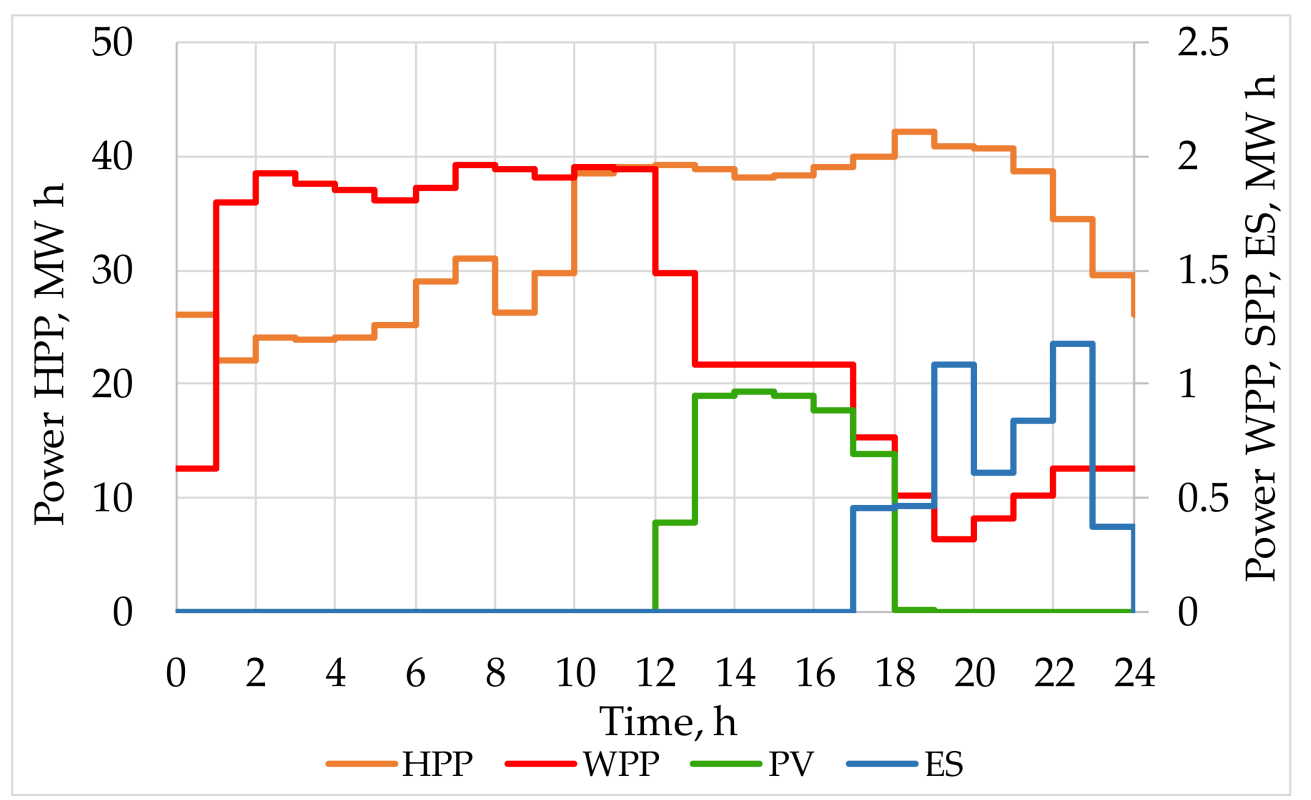

Figure 7. The optimal composition of alternative sources and energy storage to minimize the cost of power energy consumption.

The study shows that most of the daily interval, except for the periods of morning and evening peaks, renewable sources can provide coverage of electric energy consumption. However, during periods of peak load, there is a shortage of active power, which currently leads to the disconnection of power consumers or their restriction. The problem will be solved by installing an energy storage device, which should provide additional generation of stored power energy from 17 to $23 \mathrm{~h}$. In the morning hours from 6 a.m. to 12 noon, there is a high speed of the wind flow, which allows to save the energy of the storage device.

The energy storage mode in terms of the optimal power consumption in the daily interval is presented in Table 2, from which it is advisable to accumulate energy at night considering the discharge of lithium-ion batteries, which should not be lower than $20 \%$ in order to extend their service life.

Table 2. An accumulation of a power energy from various generation sources.

\begin{tabular}{|c|c|c|c|}
\hline Time, hours & $P_{H P P}, \mathrm{~kW}$ & $P_{W P P}, \mathrm{~kW}$ & $P_{P V}, \mathrm{~kW}$ \\
\hline 1 & 0 & 1000 & 0 \\
\hline 2 & 0 & 1000 & 0 \\
\hline 3 & 0 & 1000 & 0 \\
\hline 4 & 0 & 722 & 0 \\
\hline 5 & 0 & 1000 & 0 \\
\hline 6 & 0 & 278 & 0 \\
\hline 7 & 0 & 0 & 0 \\
\hline 8 & 0 & 0 & 0 \\
\hline 9 & 0 & 0 & 0 \\
\hline$\cdots$ & $\ldots$ & $\ldots$ & .. \\
\hline 24 & 0 & 0 & 0 \\
\hline
\end{tabular}


In general, the minimum financial costs of power consumers in the daily interval of a winter day will be achieved with the following ratio of alternative sources of generation and energy storage reflected in Figure 8.

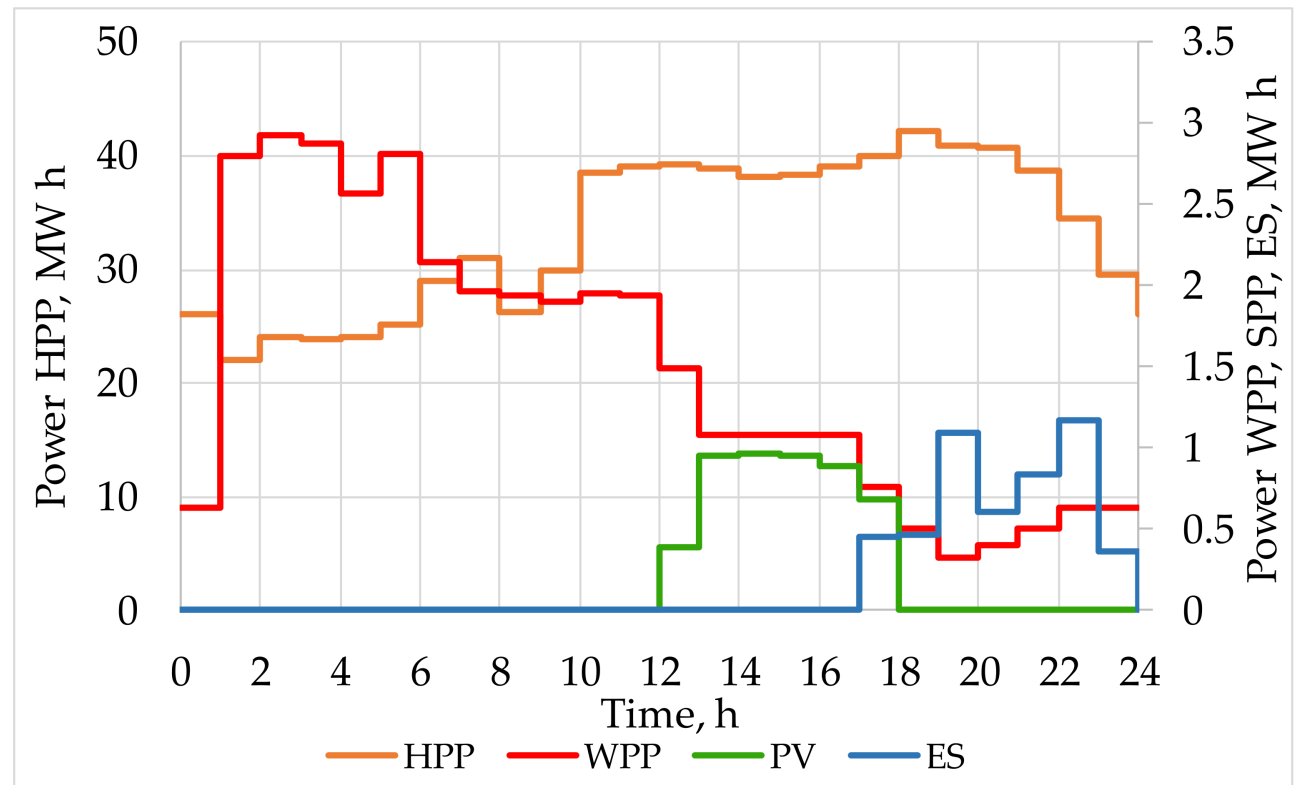

Figure 8. Selection of generating sources and energy storage devices to minimize the financial costs of electricity consumption. During this study, the most economical and efficient way of renewable and alternative energy sources joint functioning has been identified as part of the hybrid EPS aimed to achieve minimal financial costs and increase energy efficiency during such operation.

According to the obtained computation results, the electricity surplus was observed at $1-11 \mathrm{~h}$ for wind farms and at $8-16 \mathrm{~h}$ for $P V$ power plant. The results are summarized in Table 3.

Table 3. The electricity surplus.

\begin{tabular}{lcccccccccccc}
\hline $\begin{array}{c}\text { Time, } \mathbf{h} \\
\text { Power, } \mathbf{k W}\end{array}$ & $\mathbf{1}$ & $\mathbf{2}$ & $\mathbf{3}$ & $\mathbf{4}$ & $\mathbf{5}$ & $\mathbf{6}$ & $\mathbf{7}$ & $\mathbf{8}$ & $\mathbf{9}$ & $\mathbf{1 0}$ & $\mathbf{1 1}$ & $\mathbf{1 2}$ \\
\hline $\mathbf{W}_{\boldsymbol{H P P}}$ & 0 & 0 & 0 & 0 & 0 & 0 & 0 & 0 & 0 & 0 & 0 & 0 \\
$\mathbf{W}_{\boldsymbol{W P P}}$ & 861 & 340 & 30 & 0 & 463 & 1939 & 3058 & 2140 & 1364 & 622 & 34 & 0 \\
$\mathbf{W}_{\boldsymbol{P V}}$ & 0 & 0 & 0 & 0 & 0 & 0 & 0 & 81 & 969 & 1949 & 2688 & 2749 \\
$\quad$ Time, $\mathbf{h}$ & $\mathbf{1 3}$ & $\mathbf{1 4}$ & $\mathbf{1 5}$ & $\mathbf{1 6}$ & $\mathbf{1 7}$ & $\mathbf{1 8}$ & $\mathbf{1 9}$ & $\mathbf{2 0}$ & $\mathbf{2 1}$ & $\mathbf{2 2}$ & $\mathbf{2 3}$ & $\mathbf{2 4}$ \\
$\quad$ Power, $\mathbf{k W}$ & 0 & 0 & 0 & 0 & 0 & 0 & 0 & 0 & 0 & 0 & 0 & 0 \\
$\mathbf{W}_{\boldsymbol{H P P}}$ & 0 & 0 & 0 & 0 & 0 & 0 & 0 & 0 & 0 & 0 & 0 & 0 \\
$\mathbf{W}_{\boldsymbol{W P P}}$ & 2310 & 2088 & 1572 & 833 & 0 & 0 & 0 & 0 & 0 & 0 & 0 & 0 \\
$\mathbf{W}_{\boldsymbol{P V}}$ & & & & & & & & & & &
\end{tabular}

It is shown that due to the optimal management of the energy consumption in each hour of the daily time interval, minimization of the financial costs for energy consumption can be achieved, both for the region as a whole and for each electric power consumer if it has their own sources of alternative energy generation. This approach is new and corresponds to an innovative proposal for the short-term development of the examined region.

An analysis of the energy consumption modes of the presented autonomous region of the Pamirs of Republic of Tajikistan shows that for seasonal management of the power consumption, it is necessary to select the busiest working days for the winter, spring, summer and fall seasons. It showed that the most problematic daily regimes relate to the winter season, while in the summer period, all loads can be covered at the expense of water resources, including the export of excess power energy. This is caused by the mountainous 
terrain and the abundance of small rivers. The picture changes radically in winter, due to the need for heating, water heating and a higher level of lighting. The power energy export is not topical anymore.

This work is devoted solving the problems during the winter period, and it shows that they can be successfully solved in the short term taking into account the prospects for development of the mining industry, which plays a key role for the well-being of the population and solving the environmental issues based on carbon-free energy.

The steady-state mode and accordantly the voltage at the nodes of the system can be calculated after the optimal balancing of the mode has been achieved, which is the subject of this mathematical model. If this condition is satisfied, the frequency in the system will be ensured and correspond to the industrial frequency of $50 \mathrm{~Hz}$ in normal and post-emergency modes. In balanced mode, voltage and frequency will comply with the permissible deviations.

The proposed method and algorithm for optimization of energy consumption makes it possible to minimize the financial costs of several electric power consumers that have the opportunity to choose a power source from renewable (HPP energy) and alternative (WPP and PV energy) sources. The considered model includes an energy storage device, which plays the main balancing role in the EPS and thereby allows minimizing the risks of underutilization of the WPP energy, dictated by the unpredictable nature of the generation of the latter.

The advantages of the proposed method for managing energy consumption in the power system are as follows: (1) relative simplicity in comparison with more complex models; (2) versatility, which allows to replace power sources, add criteria and restrictions; (3) scalability to which the algorithm can be applied for both small generating consumers and large autonomous power systems; (4) high transparency of the control algorithm for the interpretation of each step of its work and the obtained results; and (5) low risk of error at the stage of software implementation, integration and operation of the algorithm.

\section{Conclusions}

Evaluation of the reliability of hybrid power generation systems using RES, which have significant differences in structure, control systems, types of converters used, etc., is of considerable importance in terms of optimizing energy distribution. The study has been motivated by the need to increase the economic viability of integrated renewable energy systems, and in particular, autonomous multiple energy carrier microgrids, which not only play a central role in integrating renewable energy variables as part of global efforts to address climate change and decentralize energy, but are also important for ensuring universal reliable access to affordable, reliable, sustainable and modern energy sources.

For the considered autonomous power system, hydroelectric power plants of small rivers are accepted as a renewable energy source, and wind power plants and solar power plants are accepted as alternative sources; energy storage is a balancing source.

As a result, the optimal ratio of power generation by alternative sources from daily power consumption for winter was established to be hydroelectric power plants $(94.8 \%)$, wind power plant (3.8), solar photovoltaic power plant $(0.5 \%)$ and energy storage $(0.8 \%)$. In the summer, there is no need for an optimal choice of generation sources since the entire electrical load can be covered with the energy produced by hydroelectric power plants in this region.

The paper has proposed a mathematical model to minimize the financial costs of individual generating consumers. The proposed method and algorithm for optimizing energy consumption makes it possible to minimize the financial costs of several power consumers. Optimization is based on the linear programming method with variable constraints on the daily interval. The proposed hybrid energy system and optimization of its energy consumption management is implemented based on a real and practical study for the Pamir power system; computational experiments and comparison of conditions were carried out to obtain optimal results at different energy storage capacities. The research 
results and computational experiments are presented in detailed manner, where the analysis shows that each generating consumer can independently minimize their power energy costs and maximize the benefits of the exchange.

This study considers the methodology applied to the daily interval of the busiest day. However, the optimal growth in the daily interval will not necessarily correspond to the optimum in the annual interval $(8,760 \mathrm{~h})$. Preliminary calculations show that it is important to carry out calculations every day, thereby approaching the optimal solution at longer time intervals (month, year). Optimizing financial and electricity costs at monthly and longer time intervals requires introducing additional conditions, including consideration of the possible transmission and export of the power energy system, which, in turn, is determined by the load schedule of neighboring electric power consumers as well as the selling and buying prices of electricity. Further work is planned on carrying out computational experiments based on several years' data of the considered power system; to improve the optimal control approach, including the accounting of the forecast values of consumption and generation of the power system; and to select the optimal equipment of the power plants based on renewable energy, considering economic efficiency and their impact on decarbonization in the examined power system.

Author Contributions: All authors contributed extensively to the work presented in this paper. Conceptualization, M.N., V.M., M.S., I.Z., S.B., P.M. and A.G.; methodology, M.N., V.M., M.S., I.Z., S.B., P.M. and A.G.; software, P.M. and A.G.; validation, M.N., I.Z. and S.B.; formal analysis, M.N., V.M., M.S., I.Z., S.B., P.M. and A.G.; investigation, V.M., M.S., I.Z., S.B., P.M. and A.G.; writing-original draft preparation, M.N., V.M. and A.G.; writing-review and editing, I.Z., S.B. and M.S. visualization, M.N., P.M. and A.G.; supervision, M.S., P.M., I.Z. and S.B.; project administration, M.S., I.Z. and S.B.; funding acquisition, M.N., V.M., M.S., I.Z., S.B., P.M. and A.G. All authors have read and agreed to the published version of the manuscript.

Funding: This research received no external funding.

Institutional Review Board Statement: Not applicable.

Conflicts of Interest: The authors declare no conflict of interest.

\section{References}

1. Mohseni, S.; Brent, A.C.; Burmester, D. Off-Grid Multi-Carrier Microgrid Design Optimisation: The Case of Rakiura-Stewart Island, Aotearoa-New Zealand. Energies 2021, 14, 6522. [CrossRef]

2. Climate Action. Available online: https://ec.europa.eu/clima/eu-action/international-action-climate-change/climatenegotiations / paris-agreement_en (accessed on 18 October 2021).

3. Tailor, R.; Beňa, L.; Čonka, Z.; Kolcun, M. Design of Management Systems for Smart Grid. In Proceedings of the 2021 Selected Issues of Electrical Engineering and Electronics (WZEE), Rzeszow, Poland, 13-15 September 2021.

4. Min, H.S.; Wagh, S.; Kadier, A.; Gondal, I.A.; Azim, N.A.P.B.A.; Mishra, M.K. Edition: 7 Chapter: Renewable Energy Technologies; Min, H.S., Ed.; Ideal International E-Publication Pvt. Ltd.: Indore, India, 2018.

5. Sustainable Developments. Available online: https://www.un.org/sustainabledevelopment/energy/ (accessed on 18 October 2021).

6. Zahraoui, Y.; Alhamrouni, I.; Mekhilef, S.; Basir Khan, M.R.; Seyedmahmoudian, M.; Stojcevski, A.; Horan, B. Energy Management System in Microgrids: A Comprehensive Review. Sustainability 2021, 13, 10492. [CrossRef]

7. Jurasz, J.; Canales, F.A.; Kies, A.; Guezgouz, M.; Beluco, A. A review on the complementarity of renewable energy sources: Concept, metrics, application and future research directions. Sol. Energy 2020, 195, 703-724. [CrossRef]

8. Feddaoui, O.; Toufouti, R.; Labed, D.; Meziane, S. Control of an Isolated Microgrid Including Renewable Energy Resources. Serb. J. Electr. Eng. 2020, 17, 297-312. [CrossRef]

9. John Bhatti, H.; Danilovic, M. Making the World More Sustainable: Enabling Localized Energy Generation and Distribution on Decentralized Smart Grid Systems. World J. Eng. Technol. 2018, 6, 350-382. [CrossRef]

10. Deng, Z.; Xiao, J.; Zhang, S.; Xie, Y.; Rong, Y.; Zhou, Y. Economic feasibility of large-scale hydro-solar hybrid power including long distance transmission. Glob. Energy Interconnect. 2019, 2, 290-299.

11. Li, H.; Liu, P.; Guo, S.; Ming, B.; Cheng, L.; Yang, Z. Long-term complementary operation of a large-scale hydro-photovoltaic hybrid power plant using explicit stochastic optimization. Appl. Energy 2019, 238, 863-875. [CrossRef]

12. Ausfelder, F.; Beilmann, C.; Bertau, M.; Bräuninger, S.; Heinzel, A.; Hoer, R.; Koch, W.; Mahlendorf, F.; Metzelthin, A.; Peuckert, M.; et al. Energy Storage as Part of a SecureEnergy Supply. ChemBioEng Rev. 2017, 4, 144-210. [CrossRef]

13. Li, F.F.; Qiu, J. Multi-objective optimization for integrated hydro-photovoltaic power system. Appl. Energy 2016, 167, 377-384. [CrossRef] 
14. Lawan, S.M.; Abidin, W.A.W.Z. A Review of Hybrid Renewable Energy Systems Based on Wind and Solar Energy: Modeling, Design and Optimization; Wind Solar Hybrid Renewable Energy System: London, UK, 2020; 21p. [CrossRef]

15. Burger, C.; Froggatt, A.; Mitchell, C.; Weinmann, J. Decentralised Energy: A Global Game Changer; Ubiquity Press: Berkeley, CA, USA, 2020.

16. Mohseni, S.; Brent, A.C.; Burmester, D. Community Resilience-Oriented Optimal Micro-Grid Capacity Expansion Planning: The Case of Totarabank Eco-Village, New Zealand. Energies 2020, 13, 3970. [CrossRef]

17. Matrenin, P.; Safaraliev, M.; Dmitriev, S.; Kokin, S.; Ghulomzoda, A.; Mitrofanov, S. Medium-term load forecasting in isolated power systems based on ensemble machine learning models. Energy Rep. 2022, 8, 612-618. [CrossRef]

18. Kirgizov, A.K.; Dmitriev, S.A.; Safaraliev, M.K.; Pavlyuchenko, D.A.; Ghulomzoda, A.H.; Ahyoev, J.S. Expert system application for reactive power compensation in isolated electric power systems. Int. J. Electr. Comput. Eng. 2021, 11, 3682-3691. [CrossRef]

19. Asanov, M.S.; Safaraliev, M.K.; Zhabudaev, T.Z.; Asanova, S.M.; Kokin, S.E.; Dmitriev, S.A.; Obozov, A.J.; Ghulomzoda, A.H. Algorithm for calculation and selection of micro hydropower plant taking into account hydro-logical parameters of small watercourses mountain rivers of Cen-tral Asia. Int. J. Hydrog. Energy 2021, 46, 37109-37119. [CrossRef]

20. Jurasz, J.; Dabek, P.B.; Kazmierczak, B.; Kies, A.; Wdowikowski, M. Large scale complementary solar and wind energy sources coupled with pumped-storage hydroelectricity for Lower Silesia (Poland). Energy 2018, 161, 183-192. [CrossRef]

21. Yang, Z.; Liu, P.; Cheng, L.; Wang, H.; Ming, B.; Gong, W. Deriving operating rules for a large-scale hydro-photovoltaic power system using implicit stochastic optimization. J. Clean. Prod. 2018, 195, 562-572. [CrossRef]

22. Kougias, I.; Szabo, S.; Monforti-Ferrario, F.; Huld, T.; Bódis, K. A methodology for optimization of the complementarity between small-hydropower plants and solar PV systems. Renew. Energy 2016, 87, 1023-1030. [CrossRef]

23. Parastegari, M.; Hooshmand, R.A.; Khodabakhshian, A.; Zare, A.H. Joint operation of wind farm, photovoltaic, pump-storage and energy storage devices in energy and reserve markets. Int. J. Electr. Power Energy Syst. 2015, 64, 275-284. [CrossRef]

24. Jure, M.; Zvonimir, G. Feasibility of the green energy production by hybrid solar + hydro power system in Europe and similar climate areas. Renew. Sustain. Energy Rev. 2010, 14, 1580-1590. [CrossRef]

25. Dinglin, L.; Yingjie, C.; Kun, Z.; Ming, Z. Economic evaluation of wind-powered pumped storage system. Syst. Eng. Procedia 2012, 4, 107-115. [CrossRef]

26. Bekirov, E.A.; Strizhakov, K. Optimization of load distribution modes in a combined system with renewable energy sources. Motrol 2012, 1, 146-150.

27. Ma, T.; Lashway, C.R.; Song, Y.; Mohammed, O. Optimal renewable energy farm and energy storage sizing method for future hybrid power system. In Proceedings of the 2014 17th International Conference on Electrical Machines and Systems (ICEMS), Hangzhou, China, 22-25 October 2014; pp. 2827-2832. [CrossRef]

28. Shahirinia, A.H.; Tafreshi, S.M.M.; Gastaj, A.H.; Moghaddomjoo, A.R. Optimal sizing of hybrid power system using genetic algorithm. In Proceedings of the 2005 International Conference on Future Power Systems, Amsterdam, The Netherlands, 18 November 2005; pp. 1-6. [CrossRef]

29. Gang, L.; Heqing, S.; Dragan, R. Power generation cost minimization of the grid-connected hybrid renewable energy system through optimal sizing using the modified seagull optimization technique. Energy Rep. 2020, 6, 3365-3376. [CrossRef]

30. Ma, T.; Mohammed, O. Economic analysis of real-time large scale PEVs network power flow control algorithm with the consideration of V2G services. In Proceedings of the 2013 IEEE Industry Applications Society Annual Meeting, Lake Buena Vista, FL, USA, 6-11 October 2013; pp. 1-8. [CrossRef]

31. Chen, S.X.; Gooi, H.B.; Wang, M.Q. Sizing of Energy Storage for Microgrids. IEEE Trans. Smart Grid 2012, 3, 142-151. [CrossRef]

32. Xu, L.; Ruan, X.; Mao, C.; Zhang, B.; Luo, Y. An Improved Optimal Sizing Method for Wind-Solar-Battery Hybrid Power System. IEEE Trans. Sustain. Energy 2013, 4, 774-785. [CrossRef]

33. Manusov, V.; Nazarov, M. Energy Consumption Conditions Optimization of the Autonomous System Based on Carbon-Free Energy. In Proceedings of the 2020 Ural Smart Energy Conference (USEC), Ekaterinburg, Russia, 13-15 November 2020; pp. 93-96. [CrossRef]

34. Matrenin, P.; Safaraliev, M.; Dmitriev, S.; Kokin, S.; Eshchanov, B.; Rusina, A. Adaptive ensemble models for medium-term forecasting of water inflow when planning electricity generation under climate change. Energy Rep. 2022, 8, 439-447. [CrossRef]

35. Ghulomzoda, A.; Gulakhmadov, A.; Fishov, A.; Safaraliev, M.; Chen, X.; Rasulzoda, K.; Gulyamov, K.; Ahyoev, J. Recloser-Based Decentralized Control of the Grid with Distributed Generation in the Lahsh District of the Rasht Grid in Tajikistan, Central Asia. Energies 2020, 13, 3673. [CrossRef]

36. Safaraliev, M.K.; Odinaev, I.N.; Ahyoev, J.S.; Rasulzoda, K.N.; Otashbekov, R.A. Energy Potential Estimation of the Region's Solar Radiation Using a Solar Tracker. Appl. Sol. Energy 2020, 56, 270-275. [CrossRef]

37. Shakirov, V.A.; Artemyev, A.Y. The choice of a site for the placement of a wind power plant using computer modeling of terrain and wind flow. Bull. Irkutsk State Tech. Univ. 2017, 21, 133-143. [CrossRef] 